\title{
THE INFLUENCE OF CARBON DIOXIDE ON THE GROWTH OF OBLIGATE AND FACULTATIVE ANAE- ROBES ON SOLID MEDIA
}

\author{
B. WATT \\ Department of Bacteriology, University Medical School, Edinburgh EH8 9AG
}

THE addition of carbon dioxide $\left(\mathrm{CO}_{2}\right)$ to the gas mixture in anaerobic jars has been recommended by several workers (e.g., Willis, 1964; Hobbs, Williams and Willis, 1971), and is a routine step in anaerobic procedure in this laboratory (Collee et al., 1972). However, the basis for this is empirical. Although the stimulatory effect of $\mathrm{CO}_{2}$ on spore germination is well documented (Wynne and Foster, 1948; Roberts and Hobbs, 1968; Holland, Barker and Wolf, 1970), some workers have noted that it may have an inhibitory effect on the growth of Clostridium welchii from spores (Futter and Richardson, 1971). The present paper describes quantitative studies designed to evaluate the importance of added $\mathrm{CO}_{2}$ in anaerobic jar procedure, with special reference to the recovery of essentially vegetative inocula on solid media.

\section{MATERIALS AND METHODS}

Strains. The following test strains were subcultured in cooked-meat broth (CMB): Clostridium welchii ( $\mathrm{Cl}$. perfringens) type $\mathrm{A}, \beta$-haemolytic, classical (heat-sensitive) strains, laboratory nos. L2A and $\mathrm{Cl}$, and NCTC8588; $C l$. welchii type A, non-haemolytic heatresistant strains no. NCTC8359, NCTC8238 and NCTC8239; Cl. histolyticum no. NCTC503; Cl. bifermentans lab. no. B4; Cl. septicum lab. no. 101; Cl. tetani type VI, no. NCTC9569; $\mathrm{Cl}$. tetani no. NCTC5405; $\mathrm{Cl}$. oedematiens $(\mathrm{Cl}$. novyi) type A, Glaxo no. 5277/64; $\mathrm{Cl}$. oedematiens type B, Glaxo no. 5281/64; Cl. oedematiens type D, no. NCTC8145; Bacteroides fragilis no. NCTC9343; B. necrophorus nos. NCTC7155 and NCTC10575; B. melaninogenicus nos. NCTC9336 and NCTC9337; and Bacteroides-like organisms isolated in Edinburgh from faeces or wound exudates and labelled Gram-negative anaerobic bacilli (GNAB) nos. 1-20. Five strains of Streptococcus pyogenes (Lancefield group A) were isolated from clinical material and subcultured in nutrient broth (NB).

Media. Cooked-meat broth was prepared as described by Cruickshank (1968) but the infusion broth component was made from Nutrient Broth No. 2 (Oxoid) which was also used alone for the subculture of some of the test strains. "Pre-steamed nutrient broth" was used as a diluent in quantitative studies; it was heated by steaming at $100^{\circ} \mathrm{C}$ for 30 min. to remove dissolved air, then cooled rapidly to $37^{\circ} \mathrm{C}$.

Blood-agar plates were prepared with Oxoid Blood Agar Base No. 2 enriched with equine blood (10 per cent.). Watt's modification of Moore's medium (cysteine-dithiothreitol equine blood agar, CDEBA) was used for the surface growth of $\mathrm{Cl}$. oedematiens strains (Watt, 1972). All plates contained 1.2 per cent. agar unless specified otherwise in the text.

Blood. Defibrinated equine blood was supplied by Wellcome Laboratories.

Anaerobic jar procedure. In the present study, Baird and Tatlock (BTL) anaerobic jars were used. Each jar was equipped with three room-temperature catalyst sachets. The detailed anaerobic jar procedure was basically that described by Collee et al. (1972); in addition, jars were evacuated again after being filled with a mixture of 90 per cent. hydrogen

Received 26 Oct. 1972; accepted 10 Dec. 1972.

J. MED. MICROBIOL.-VOL. 6 (1973) 
$\left(\mathrm{H}_{2}\right)$ and 10 per cent. carbon dioxide $\left(\mathrm{CO}_{2}\right)$ and then refilled with this gas mixture before incubation. All cultures were incubated at $37^{\circ} \mathrm{C}$.

Gases. Cylinders of $\mathrm{CO}_{2}$ were supplied by Distillers Company Ltd. Cylinders of $\mathrm{H}_{2}$ and a special gas mixture of $\mathrm{H}_{2} 90$ per cent. with $\mathrm{CO}_{2} 10$ per cent. were supplied by British Oxygen Co. Ltd.

Counting methods. Viable counts performed by a spread-plate method (Watt) were calculated from the mean result obtained from ten plates seeded from a predetermined dilution that gave 100-700 discrete colonies per plate.

Antiserum. An experimental antiserum no. Ex.3567, supplied by Wellcome Research Laboratories, was used to control the growth of the $\mathrm{Cl}$. septicum strain (Watt).

\section{RESULTS}

\section{Enhancement of recovery of laboratory strains with carbon dioxide}

Preliminary studies indicated that enhancement of growth of certain anaerobes, notably Gram-negative anaerobes, occurred if 10 per cent. carbon dioxide was added to the hydrogen gas used in anaerobic jars purchased from Baird and Tatlock Ltd ("BTL jars"). Both the size and number of colonies were increased, but there was no further enhancement with concentrations of $\mathrm{CO}_{2}$ above 10 per cent. and the enhancement was less marked with concentrations of $\mathrm{CO}_{2}$ below 10 per cent. A series of statistically designed experiments was therefore developed to compare the recovery of clinically important anaerobes in BTL jars with and without the addition of 10 per cent. $\mathrm{CO}_{2}$ in the gas mixture.

Appropriate dilutions (see Materials and methods) of the test broth cultures were made in pre-steamed nutrient broth and were used to seed replicate plates of freshly poured 10 per cent. equine blood agar (EBA). The seeded plates were randomly distributed between two or more BTL anaerobic jars and the position of each plate within a given jar was also randomised. Half of the jars were processed with added $\mathrm{CO}_{2}$ and half with $\mathrm{H}_{2}$ only; the order of processing of the jars was randomised. All the jars in a given experiment were incubated for identical periods of time.

Of the clostridia tested, the recovery of $\mathrm{Cl}$. tetani was significantly improved by the addition of 10 per cent. $\mathrm{CO}_{2}$ (table $\mathrm{I}$ ), as was the size of colony observed with this non-motile strain. Similar results were obtained with type-A and type-B strains of $\mathrm{Cl}$. oedematiens grown on CDEBA medium with 4 per cent. agar and the zones of haemolysis were increased. None of the other clostridia tested showed significant enhancement of recovery with added $\mathrm{CO}_{2}$.

The results of experiments with Bacteroides strains (table II) show that addition of $\mathrm{CO}_{2}$ to the incubation environment markedly increased the number and size of colonies grown on EBA medium. Although easily visible colonies were obtained after overnight incubation in $\mathrm{H}_{2}+\mathrm{CO}_{2}$, at best only pin-point colonies were observed on plates incubated in $\mathrm{H}_{2}$, and incubation for a further $48 \mathrm{hr}$ was necessary before countable colonies were obtained on these plates.

Twenty strains of Gram-negative strictly anaerobic bacilli ("Bacteroideslike organisms "), isolated from wounds and from human faeces and not further characterised, were then tested as described above. All 20 strains showed good growth with development of countable colonies after incubation for $18 \mathrm{hr}$ in 
$\mathrm{H}_{2}+\mathrm{CO}_{2}$. When incubated in $\mathrm{H}_{2}$ without $\mathrm{CO}_{2}$, two strains showed no growth even after prolonged incubation and the remaining 18 strains required incubation for up to $96 \mathrm{hr}$ for the development of countable colonies. Of these 18

TABLE I

Recovery of a strain of Clostridium tetani from a dilution of a CMB culture grown anaerobically on $E B A^{*}$ medium in $B T L$ jars with and without carbon dioxide

\begin{tabular}{lcccc}
\hline Test culture & $\begin{array}{c}\text { Jar } \\
\text { number }\end{array}$ & Gas used & $\begin{array}{c}\text { Mean colony } \\
\text { count } \pm \text { S.E. } \dagger\end{array}$ & $t$-valueł \\
\hline $\begin{array}{l}\text { 18-hr CMB culture of } \mathrm{Cl} . \\
\begin{array}{l}\text { tetani type VI, no. } \\
\text { NCTC9569 }\end{array}\end{array}$ & C7 & $\begin{array}{c}90 \text { per cent. } \mathrm{H}_{2}+10 \text { per } \\
\text { cent. CO }\end{array}$ \\
C5 & 100 per cent. $\mathrm{H}_{2}$ & $1014 \cdot 0 \pm 27 \cdot 8$ & $\begin{array}{c}3.06 \\
893.0 \pm 28.1\end{array}$ & $(\mathrm{P}<0.01)$ \\
\hline
\end{tabular}

* $\mathrm{EBA}=10$ per cent. equine blood agar.

$\dagger$ Colony count expressed as mean \pm S.E. (standard error of the mean) derived from ten replicate plates, each seeded with $0.02 \mathrm{ml}$ of a $0.5 \times 10^{-3}$ dilution of the test culture.

Plates were incubated for $48 \mathrm{hr}$.

$\ddagger t$-value for difference of means on 18 degrees of freedom.

strains, ten showed significantly decreased colony counts on plates incubated in $\mathrm{H}_{2}$ alone. The ultimate recovery of the remaining eight strains was not significantly affected by the absence of $\mathrm{CO}_{2}$ although the rate of the development of colonies was much slower.

TABLE II

Recovery of Bacteroides strains from dilutions of $C M B$ cultures grown anaerobically on $E B A^{*}$ medium in BTL jars with and without carbon dioxide

\begin{tabular}{|c|c|c|c|c|}
\hline Test strain & $\underset{\text { Jar }}{\text { number }}$ & Gas used & $\begin{array}{l}\text { Mean colony } \\
\text { count } \pm \text { S.E. } \dagger\end{array}$ & $t$-value§ \\
\hline $\begin{array}{l}\text { 18-hr CMB culture of Bac- } \\
\text { teroides necrophorus } \\
\text { no. NCTC } 7155\end{array}$ & $\begin{array}{l}\mathrm{C} 5 \\
\mathrm{C} 7\end{array}$ & $\begin{array}{l}10 \text { per cent. } \mathrm{CO}_{2}+90 \text { per } \\
\text { cent. } \mathrm{H}_{2} \\
100 \text { per cent. } \mathrm{H}_{2}\end{array}$ & $\begin{array}{l}739 \cdot 6 \pm 21 \cdot 2 \\
17 \cdot 8 \pm 3 \cdot 5 \ddagger\end{array}$ & $\begin{array}{c}3.36 \\
(P<0.001)\end{array}$ \\
\hline $\begin{array}{l}\text { 18-hr CMB culture of } B . \\
\text { fragilis no. NCTC } 9343\end{array}$ & $\begin{array}{l}\mathrm{C} 3 \\
\mathrm{C} 4\end{array}$ & $\begin{array}{l}10 \text { per cent. } \mathrm{CO}_{2}+90 \text { per } \\
\text { cent. } \mathrm{H}_{2} \\
100 \text { per cent. } \mathrm{H}_{2}\end{array}$ & $\begin{array}{r}1153 \cdot 0 \pm 32 \cdot 4 \\
873 \cdot 0 \pm 26 \cdot 4 \ddagger\end{array}$ & $\begin{array}{c}6.7 \\
(P<0.001)\end{array}$ \\
\hline
\end{tabular}

* $\mathrm{EBA}=10$ per cent. equine blood agar.

$\dagger$ Colony count expressed as mean \pm S.E. (standard error of mean) derived from ten replicate plates, each seeded with $0.02 \mathrm{ml}$ of a $0.5 \times 10^{-3}$ dilution of the test culture.

$\ddagger$ Plates incubated in 100 per cent. $\mathrm{H}_{2}$ required prolonged incubation $(72 \mathrm{hr})$ for the development of easily visible colonies; plates incubated in $\mathrm{H}_{2}+\mathrm{CO}_{2}$ for $18 \mathrm{hr}$.

$\S t$-value for difference of means on 18 degrees of freedom.

The growth of five strains of beta-haemolytic streptococci (Lancefield group A) was compared in jars with and without the addition of 10 per cent. $\mathrm{CO}_{2}$.

J. MED. MICROBIOL.-VOL. 6 (1973) 
Two of the test strains showed significantly improved recovery in the presence of added $\mathrm{CO}_{2}$ (table III); the colony counts of other strains were not significantly affected. In all cases, however, the size of the colonies, and of the zones of haemolysis, as well as the degree of haemolysis observed, were greater in the presence of $\mathrm{CO}_{2}$.

The influence of 10 per cent. carbon dioxide on the growth of anaerobic organisms from samples of human faeces

Because Bacteroides spp. form a major component of the faecal flora, and the growth of our test strains was enhanced by added $\mathrm{CO}_{2}$, the yield of anaerobic

TABLE III

Recovery of two strains of Streptococcus pyogenes from dilutions of broth cultures grown anaerobically on $E B A^{*}$ medium in BTL anaerobic jars with and without carbon dioxide

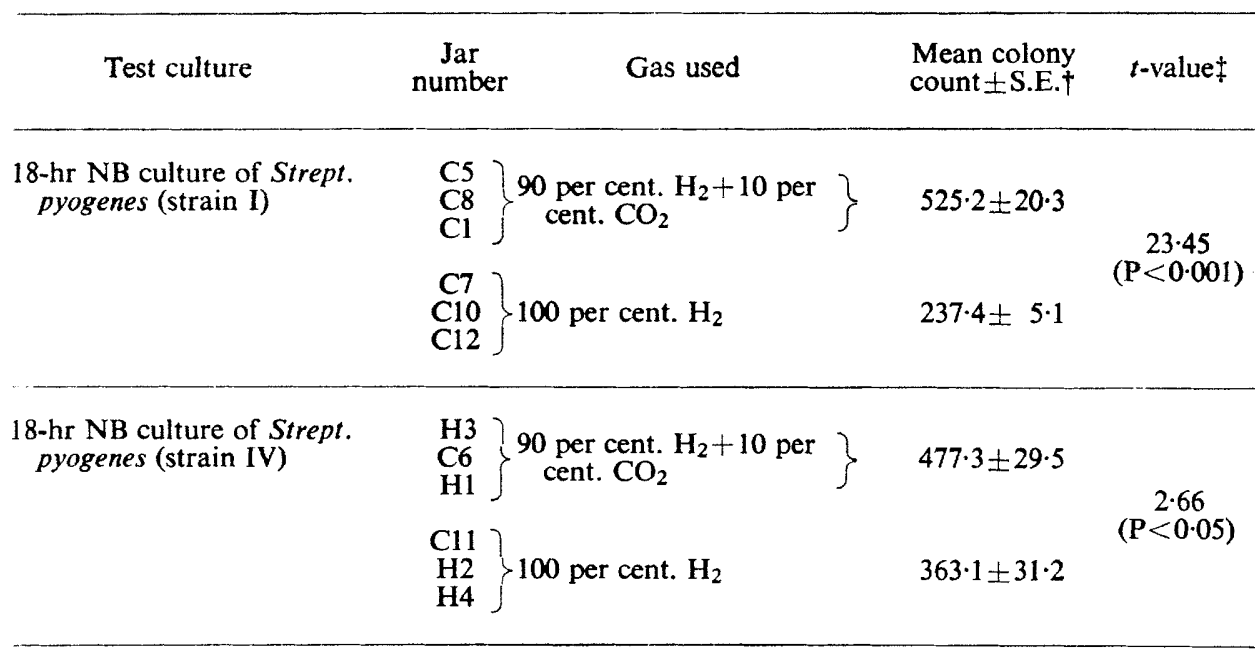

* EBA $=10$ per cent. equine blood agar.

$\dagger$ Colony count expressed as mean \pm S.E. (standard error of the mean) derived from nine replicate plates, each seeded with $0.02 \mathrm{ml}$ of a $10^{-4}$ dilution of the test organism.

Plates were incubated for $18 \mathrm{hr}$.

$\ddagger t$-value for difference of means on 16 degrees of freedom.

organisms (" total anaerobes ") from faecal samples was compared on plates incubated in anaerobic jars with and without the addition of 10 per cent. $\mathrm{CO}_{2}$. Weighed portions of freshly passed samples of faeces were diluted in presteamed nutrient broth and the dilutions were used to seed plates that were then processed as described above. The results of a typical experiment (table IV) show that the colony count of total anaerobes is increased more than three-fold if $\mathrm{CO}_{2}$ is added to the incubation environment.

\section{Investigation of possible inhibitory effects of carbon dioxide}

In the present study there was little evidence of inhibition of growth of strains by $\mathrm{CO}_{2}$; the test strain of $\mathrm{Cl}$. histolyticum showed slight inhibition and 
one strain of $\mathrm{Cl}$. welchii (C1) showed slight inhibition on one occasion that was not reproducible in further replicate experiments. None of the other $C l$.

\section{TABLE IV}

Yield of anaerobic organisms from a dilution of a sample of human faeces grown anaerobically on $E B A^{*}$ medium in $B T L$ jars with and without carbon dioxide

\begin{tabular}{|c|c|c|c|}
\hline Jar number & Gas used & $\begin{array}{l}\text { Mean colony } \\
\text { count } \pm \text { S.E. } \dagger\end{array}$ & $t$-valuef \\
\hline $\left.\begin{array}{l}\text { C8 } \\
\text { C9 }\end{array}\right\}$ & $\begin{array}{l}90 \text { per cent. } \mathrm{H}_{2}+10 \text { per } \\
\text { cent. } \mathrm{CO}_{2}\end{array}$ & \} $483 \cdot 0 \pm 7 \cdot 2$ & \multirow{2}{*}{$\begin{array}{c}34.35 \\
(P<0.001)\end{array}$} \\
\hline $\left.\begin{array}{l}\mathrm{C} 6 \\
\mathrm{H} 1\end{array}\right\}$ & 100 per cent. $H_{2}$ & $149 \cdot 1 \pm 6 \cdot 6$ & \\
\hline
\end{tabular}

* $\mathrm{EBA}=10$ per cent. equine blood agar.

$\dagger$ Each colony count expressed as mean \pm S.E. (standard error of the mean) of 20 replicate plates, each seeded with $0.02 \mathrm{ml}$ of $0.5 \times 10^{-6}$ dilution of a faecal sample, and incubated for $72 \mathrm{hr}$.

$\ddagger t$-value for difference of means on 38 degrees of freedom.

\section{TABLE V}

Recovery of two strains of $\mathrm{Cl}$. welchii from diluted samples of 5-hr CMB cultures grown anaerobically on $E B A^{*}$ medium in BTL jars with and without carbon dioxide

\begin{tabular}{|c|c|c|c|}
\hline Test culture & $\begin{array}{c}\text { Jar } \\
\text { number }\end{array}$ & $\begin{array}{l}\text { Mean colony } \\
\text { count } \pm S . E . \S\end{array}$ & $t$-value $\mid$ \\
\hline $\begin{array}{l}\text { 5-hr CMB culture† of } C l . \\
\text { welchii no. NCTC8359 }\end{array}$ & 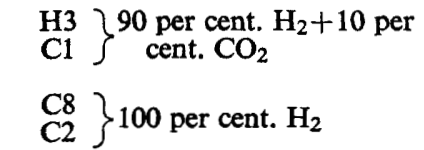 & $\begin{array}{l}437 \cdot 0 \pm 15 \cdot 6 \\
461 \cdot 9 \pm 17 \cdot 4\end{array}$ & $\begin{array}{c}1.06 \\
(P>0.05)\end{array}$ \\
\hline 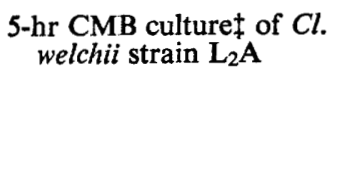 & 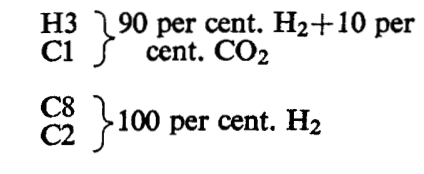 & $\begin{array}{l}695 \cdot 0 \pm 18 \cdot 6 \\
632 \cdot 4 \pm 26 \cdot 4\end{array}$ & $\begin{array}{c}1.95 \\
(P>0.05)\end{array}$ \\
\hline
\end{tabular}

* $\mathrm{EBA}=10$ per cent. equine blood agar.

$\dagger$ The total cell count was $1.6 \times 10^{8}$ per ml; the spore estimate was $<3.2 \times 10^{5}$ per ml (no spores seen in over 500 cells counted).

$\ddagger$ The total cell count was $1.7 \times 10^{8}$ per ml; the spore estimate was $<3.4 \times 10^{5}$ per $\mathrm{ml}$ (no spores seen in over 500 cells counted).

$\S$ Colony counts expressed as means \pm S.E. (standard error of the mean) derived from 20 replicate plates, each seeded with $0.02 \mathrm{ml}$ of a $0.25 \times 10^{-3}$ dilution of the parent culture.

If $t$-value for difference of means on 38 degrees of freedom.

welchii strains tested showed any inhibition of growth by $\mathrm{CO}_{2}$, either when overnight cultures were used, or when young (5-hr) cultures were used in which spores were not abundant (table V). Similarly, no inhibition was found with the Gram-negative anaerobes tested. In jars that contained no $\mathrm{H}_{2}$ (i.e., 
evacuated and filled with $\mathrm{CO}_{2}$ alone) so that the atmosphere was predominantly $\mathrm{CO}_{2}$ but not strictly anaerobic, none of the Gram-negative anaerobes grew; however the $\mathrm{Cl}$. welchii strains and one $\mathrm{Cl}$. bifermentans strain grew in this atmosphere.

\section{Discussion}

The addition of carbon dioxide to the incubation environment in anaerobic jars has often been recommended, yet there is a lack of supporting quantitative data, especially in relation to the yield of anaerobes on solid media. The present study, with statistically designed experiments, has clearly shown that addition of $\mathrm{CO}_{2}$ in a concentration of 10 per cent. to anaerobic jars increases the recovery on solid media of laboratory strains of clinically important anaerobes and of anaerobes from faecal samples. Concentrations of $\mathrm{CO}_{2}$ below 10 per cent. were less effective, and concentrations above 10 per cent. did not increase the yield further. Exuberance of growth as measured by colony size and numerical recovery were both increased in the presence of added $\mathrm{CO}_{2}$. This effect was most noticeable in the case of the Gram-negative anaerobes, but was also found with some test strains of clostridia such as $\mathrm{Cl}$. tetani. Just as Holland, Barker and Wolf (1970) noted that the enhancing effect of $\mathrm{CO}_{2}$ on spore germination varied with different test strains and was influenced by ingredients in the medium, it is reasonable to assume that the effects of $\mathrm{CO}_{2}$ observed in the present study may be similarly influenced. This requires further investigation.

Anaerobic conditions have been recommended for the isolation of betahaemolytic streptococci (Jones et al., 1941; Brumfitt and Masters, 1959), and are known to facilitate the development of easily recognisable haemolytic colonies (Fry, 1933). In the present study, the presence of 10 per cent. $\mathrm{CO}_{2}$ during anaerobic incubation significantly improved the recovery of two strains of haemolytic streptococci. If this finding can be shown to be applicable to other strains it has clear relevance for the diagnostic laboratory.

Although Futter and Richardson (1971) found that recovery from spores of $\mathrm{Cl}$. welchii was inhibited by even small amounts of $\mathrm{CO}_{2}$, no inhibition of growth of these organisms was noted in the present study when essentially vegetative inocula from $\mathrm{CMB}$ cultures were grown on blood agar; indeed all of the test strains of $\mathrm{Cl}$. welchii grew well in relatively pure $\mathrm{CO}_{2}$. Similarly, no inhibition of growth of the Gram-negative non-sporing anaerobes was found if 10 per cent. $\mathrm{CO}_{2}$ was used in the anaerobic atmosphere, although the test strains would not grow in relatively pure " non-anaerobic" $\mathrm{CO}_{2}$.

It has recently been reported (Ingham et al., 1970) that the addition of $\mathrm{CO}_{2}$ to the incubation environment has a pronounced effect on the susceptibility of a Gram-negative anaerobe to certain antibiotics in vitro, and can therefore affect the performance and interpretation of disk-sensitivity tests. It could be argued, therefore, that the addition of $\mathrm{CO}_{2}$ to anaerobic jars will lead to misleading results and is not justified. Disk-sensitivity testing is valid, however, only if satisfactory growth (as measured by the number and size of colonies developed) is achieved with reasonable speed; my results suggest that if $\mathrm{H}_{2}$ 
alone is used, prolonged incubation is necessary before this can be achieved. The problems attending the use of $\mathrm{CO}_{2}$ in this context, e.g., $p \mathrm{H}$ changes and other factors affecting antibiotic action, must be solved without excluding $\mathrm{CO}_{2}$ and they merit further study.

The observed growth-enhancing effect of $\mathrm{CO}_{2}$ for non-sporing anaerobes is of special diagnostic importance in relation to the increasing role of these organisms in serious infections of man (Sencer, 1971; Felner and Dowell, 1971). Thus, the assured provision of $\mathrm{CO}_{2}$ by the Gaspak system or as a part of a routine anaerobic procedure (see Collee et al., 1972) now merits the attention of the clinical microbiologist when he attempts to isolate clinically important anaerobes on solid media.

\section{SUMmaRY}

The quantitative recovery of test strains of bacteria on blood agar media was compared in Baird and Tatlock anaerobic jars with and without additional $\mathrm{CO}_{2}$ in the gas mixture. Both the colony size and the colony count of Gramnegative anaerobes and some of the test strains of clostridia were increased in the presence of added $\mathrm{CO}_{2}$. An enhancing effect was also noted with two strains of haemolytic streptococci. The addition of 10 per cent. $\mathrm{CO}_{2}$ as a part of routine anaerobic procedure is recommended for the diagnostic service laboratory.

I am indebted to Dr J. G. Collee for much support and helpful guidance, and to $\mathrm{Mr} \mathbf{R}$. Brown for his skilled technical assistance. The support of the Medical Research Council (Grant G 971/113/B) for the development of these studies is gratefully acknowledged.

\section{REFERENCES}

BrumfitT, W., AND MASTERS, P. L. 1959. The use of selective media for the detection of beta-haemolytic streptococci. J. R. Army Med. Cps., 105, 38.

Collee, J. G., WATt, B., Fowler, Elizabeth B., AND Brown, R. 1972. An evaluation of the Gaspak system in the culture of anaerobic bacteria. J. Appl. Bact., 35, 71.

Cruickshank, R. 1968. Medical microbiology, 11th ed. (revised reprint), Edinburgh and London, p. 757.

Felner, J. M., AND Dowell, V. R. 1971. Bacteroides bacteraemia. Am. J. Med., 50, 787.

FrY, R. M. 1933. Anaerobic methods for the identification of haemolytic streptococci. J. Path. Bact., 37, 337.

FUTTER, B. V., AND RICHARDSON, G. 1971. Anaerobic jars in the quantitative recovery of clostridia. In Isolation of anaerobes (Soc. Appl. Bact. Tech. Series, no. 5), edited by D. A. Shapton and R. G. Board, London and New York, pp. 81-91.

HobBs, G., Williams, KathleEN, AND Willis, A. T. 1971. Basic methods for the isolation of clostridia. In Isolation of anaerobes (Soc. Appl. Bact. Tech. Series, no. 5) edited by D. A. Shapton and R. G. Board, London and New York, p. 1.

Holland, Diana, Barker, A. N., and Wolf, J. 1970. The effect of carbon dioxide on spore germination in some clostridia. J. Appl. Bact., 33, 274.

Ingham, H. R., Selkon, J. B., Codd, A. A., AND Hale, J. H. 1970. The effect of carbon dioxide on the sensitivity of Bacteroides fragilis to certain antibiotics in vitro. J. Clin. Path., 23, 254.

Jones, Marion, Holmes, Lida F., AND Hale, W. M. 1941. Relative efficiency of aerobic and anaerobic methods in the isolation of beta-haemolytic streptococci. J. Bact., 42, 138. 
Roberts, T. A., AND HoBBs, G. 1968. Low temperature growth characteristics of clostridia. J. Appl. Bact., 31, 75.

SENCER, D. J. 1971. Emerging diseases of man and animals. A. Rev. Microbiol., 25, 465.

WATT, B. 1972. The recovery of clinically important anaerobes on solid media. J. Med. Microbiol., 5, 211.

Willis, A. T. 1964. Anaerobic bacteriology in clinical medicine, 2nd ed., London, p. 14.

Wynne, E. S., AND FosTer, J. W. 1948. Physiological studies on spore germination with special reference to Clostridium botulinum. III: Carbon dioxide and germination, with a note on carbon dioxide and aerobic spores. J. Bact., 55, 331. 